\title{
Thoughts and Suggestions on Problems Existing in the Construction of High Quality Curriculum Intelligence Measurement
}

\author{
YANG Bo \\ Electronic Information Department \\ Foshan University \\ Foshan Guang Dong, China \\ e-mail: fsttww@sohu.com
}

\author{
HAO ZHONG-KAO \\ Electronic Information Department \\ Foshan University \\ Foshan Guang Dong, Chin \\ e-mail: 2823855494@qq.com
}

\begin{abstract}
Intelligent measurement is an important professional course of electronic information engineering, its quality directly affect the subsequent related professional course learning effect. This paper analyzed characteristics of the course, characteristic, find out the reasons of the problems exist in the process of curriculum construction, further clarify the train of thought, the development of curriculum in the process of curriculum construction of teaching contents, teaching methods, teaching means, practical teaching links, and proposed to improve the examination reform, suggestions and concrete operating methods.
\end{abstract}

Keywords-Intelligent measurement; Quality curriculum; Curriculum construction;teaching quality; Quality curriculum

\section{INTRODUCTION}

An outstanding scientist Mendeleev once said "no measurement, no science". Electronic information science is the symbol of modern science and technology, the three pillars of it is: information acquisition (test / Measurement Technology) transmission technology, information processing technology (ICT), information (computer technology), to obtain the information of the three is the most important, because the intelligent measurement is an important means of access to information, an important indicator of the course is training students "practical ability". Therefore, my school and other colleges and universities in many engineering, especially electronic information specialty, are the "fundamental course as an important intelligent measurement". In my school, "the construction of intelligent measurement" course followed the discipline construction pace, in the mutual promotion and the commitment of the scientific study, to adapt to the development of intelligent measurement rules, nearly half a century has achieved fruitful results, achieved fruitful results in the intelligent measuring teaching, scientific research. The teaching contents are told from information, signal, the height of the system, break through the traditional teaching mode, course system follows a path from static to dynamic, steady clues, based on the time domain, frequency domain and data fields is a new structural system, hierarchical lines clear, scientific and reasonable system structure. Because the professional course is specially engaged in the important fixed-point units intelligent measurement technology and electronic instruments of teaching and scientific research, to carry out long-term intelligent measurement field of professional teaching and a high level of scientific research work, therefore able to grasp new technology development dynamic intelligent measurement field, and timely reflect to the course. Pay attention to the teaching content and course system innovation. Based on the syllabus as the basis, follow the scientific nature of the teaching content, advanced and applicable principles, to take full account of the measurement subject itself and other subjects closely related, from the information science and technology, signal, the system point of view to observe and understand the intelligent measurement and instrument technology, break through the traditional ways of measurement, the measurement accuracy of statement, open-minded, content is quite new, rather the depth. In the system, the measurement techniques in time domain, frequency domain and the number of signal and system domain as the main line to form a new structure, content arrangement and care in the traditional manner parameters measurement, compared with the similar course of Chinese novel, content, characteristic.

\section{COURSE CHARACTERISTICS AND FEATURES}

The teaching contents are told from information, signal, the height of the system, break through the traditional teaching mode, course system follows a path from static to dynamic, steady clues, based on the time domain, frequency domain and data fields is a new structural system, hierarchical lines clear, scientific and reasonable system structure. The reform of experimental teaching curriculum reflects the advanced, comprehensive, innovative and open, open remote interactive experiment course based on virtual and network technology made a successful exploration for the reform of experiment teaching mode in the future. Since entering the new century, increased the course content and training means reform and innovation, the research and Practice on the reform of the virtual electronic experiment environment 
construction and the experimental teaching method, on this basis, cultivate and bring up a batch of high level teaching team, to create a favorable situation for further development. Many courses in the teaching content, teaching methods and means, evaluation methods of reform, the teaching effect for students and industry recognition. Reform and innovation highlights the following features:

because of the professional curriculum is specialized in important fixed-point units intelligent measurement technology and electronic instruments of teaching and scientific research, to carry out long-term intelligent measurement field of professional teaching and a high level of scientific research work, it can grasp the development of intelligent measurement technology in the field of dynamic, and timely reflect to the course. Pay attention to the teaching content and course system innovation. Based on the syllabus as the basis, follow the scientific nature of the teaching content, advanced and applicable principles, to take full account of the measurement subject itself and other subjects closely related, from the information science and technology, signal, the system point of view to observe and understand the intelligent measurement and instrument technology, break through the traditional ways of measurement, the measurement accuracy of statement, open-minded, content is quite new, rather the depth. In the system, the measurement techniques in time domain, frequency domain and the number of signal and system domain as the main line to form a new structure, content arrangement and care in the traditional manner parameters measurement, compared with domestic curriculum and teaching materials, novel content, characteristic.

(2) according to the course with strong practicality, comprehensive, from the experimental teaching stage, innovative and open principle, reform of experiment teaching content and methods. In addition to retain the traditional intelligence measurement experiment, introduced the virtual instrument experimental advanced. The realization of the intelligent, automation, virtualization and network intelligent measuring experiment. Many instead of the traditional instrument using virtual instrument experimental increases in experimental teaching, and to achieve the online real-time interactive experiment, students in the remote operation to finish the experiment, in the experiment teaching construction has taken a major step, experimental reform of clear thinking, conception innovation achievements, distinctive characteristics, advanced technology, outstanding effect, achieved the leading domestic level, has the good demonstration and popularization value in Colleges and universities.

(3) make full use of network platform, take the student as the main body, strengthen the extra-curricular teacherstudent interaction, classroom time is limited, and fully mobilize the existing resources, to the traditional platform as the guide, with the network platform for media, upload video tapes, courseware and so on, can realize the real-time test and real time interaction, breaking the time barrier, communication channel through and the students' knowledge, to achieve zero distance butt.(4) focus on process assessment ability, double certificates, pay attention to the students' learning process management, learning ability and learning initiative to improve; pay attention to the students' ability to use the knowledge to analyze problems, to solve the problem of the study; pay attention to the cultivation of students' innovation ability and practice ability. Skills to meet certain requirements of students, can apply for the relevant occupation qualification certificate or Senior occupation qualification certificate. To obtain the occupation qualification certificate, in turn, promote the students' enthusiasm and initiative.

(4) focus on process assessment ability, double certificates, pay attention to the students' learning process management, learning ability and learning initiative to improve; pay attention to the students' ability to use the knowledge to analyze problems, to solve the problem of the study; pay attention to the cultivation of students' innovation ability and practice ability. Skills to meet certain requirements of students, can apply for the relevant occupation qualification certificate or Senior occupation qualification certificate. To obtain the occupation qualification certificate, in turn, promote the students' enthusiasm and initiative.

(5) the school enterprise cooperation, continuous assessment reform, completed the "reform effect + efficiency + standard" assessment methods, improve student learning initiative. In the process of educational reform, and continue to learn from foreign advanced curriculum evaluation idea and performance evaluation mode, through a pilot study, and gradually explore mechatronic specialty course examination mode with ability as standard, strengthen the examination of "teaching", "learning", "learning" function. In the examination and the proposition of guiding ideology, emphasize "exam" concept, will "qualified line" in the professional orientation decomposition to the requirements of the course, the course requires students should master the skills and knowledge, occupation ability should achieve "should know", "should" target. In the appraisal content, increase the analysis, the ability to solve practical problems and occupation quality cultivation effect of the assessment, changing the mechanical memory status problem dominated problems, simple to understand. Assessment: Theory and practice two parts. Practical knowledge assessment focuses on the skills of the students operation ability, in the training room, the theoretical knowledge examination focuses on students' flexible use of knowledge ability, in the classroom.

In the process of evaluation of students, if students are not to explain where, teachers can be in the form of questions ask students to answer, to understand students' mastery of content. Considering the cooperation problem between the question of time and students, in the process to explore the appraisal model, we adopt a cooperative manner, each group of $2 \sim 3$, the examination, carries on the explanation to 1 students, to explain the time limit within 10 minutes, the other students can be added, and the key answer the teacher's question. The end of the lecture, the teacher can participate 
in evaluation of free inquiry, then according to each student to explain and answer the questions given in the case of the team of student achievement. This way of evaluation, received generally welcome students, can really make students change from passive learning to active learning.

\section{CURRICULUM DEVELOPMENT AND PROBLEMS}

Discussions with market research and school teaching expert, thinks "intelligent measuring" course should meet the "enterprises engaged in equipment intelligent measuring instrument production, engineering test, detection and prosecution, scientific research and development" and other occupation post related knowledge, ability, quality requirements. Therefore, from the industry and occupation post the actual work needs, and to consider the student to the senior management in the enterprise development needs, select teaching content. The teaching content of courses about the learning goal setting, with a typical task as the carrier, the design of teaching situation, to act in accordance with the field from the shallower to the deeper, construction of teaching content of the order from easy to difficult, using the theory of match practice, integration of theory with practice, ordering. On the teaching organization and arrangement, the course content and the teaching process, using multimedia teaching means modernization. Pay attention to the combination of theory teaching and practice teaching, the implementation of practice teaching and virtual simulation teaching students. Practical teaching with the specified title and title combination, since the topic can be combined with students' innovation competition, in order to stimulate the students' creative thinking, to achieve the purpose of competitive learning. In addition to the hardware structures and software training platform to build the virtual experiment environment of organic coordination, financial knowledge, ability, quality education, the teaching system of three-dimensional teaching environment, extended from class to class. Professional skills training is mainly reflected in the practice of teaching, the carrier: Practice on campus and off campus internship. According to the specific requirements of training vocational ability, occupation quality and combined with the specific characteristics of course, determine the task of teaching training at the core curriculum. Through school enterprise cooperation, internship training base of the post, the combination of engineering throughout the whole process of personnel training. According to this idea, the curriculum deficiencies still exist:

(1) the campus network environment of intelligent measuring suspended course construction has begun to take shape, but not perfect, we have many plans have not had time to realize, such as: online training system, online examination system, experiment, virtual experiment system. This is we should improve and strengthen the construction of the future work.

(2) the practice of intelligent measurement program has made great achievements, but in some problems remains to be further studied and improved, such as: laboratory allweather open, offering innovative experiments, how to effectively organize, remains to be further optimized..

\section{THE REFORM GOAL OF CURRICULUM CONSTRACTION}

Intelligent measurement in the course of teaching method and means to conduct a series of reform and innovation. On the teaching method, the task of the project into the curriculum, theory of teaching will be included in the project training, to enable students to master the theory of knowledge, learning in practice, production of new technology, new methods, new technology into classroom, teaching method, teaching form and flexible application. In the means of teaching, make full use of modern multimedia teaching, modern science and technology fully applied in the teaching reform. So far, the syllabus, electronic courseware, network teaching, exercises and answers, experimental guidance and experimental procedures, reference materials, classroom video have Internet access. Our next step according to the construction goal and the implementation steps to further improve, enrich and perfect, teaching methods used are: (1) the project teaching, task driven. The training contents and their own conditions, starting from the purpose of higher education, the teaching contents are divided into several modules, thus, from the shallower to the deeper, raised by the foundation to do, while taking the project teaching method, let the students understand the training task, through the analysis and solution for the project, students will learn the knowledge applied to specific projects, to learn to use. (2) the interactive teaching, combination of teaching. The interaction between teachers and students, enhance students' ability to analyze and solve practical problems, the teaching changes the traditional teaching model integration model for teaching, through the reform of teaching mode, change the students' memory, simple to understand learning at present. (3) heuristic teaching, innovation, increase the discussion course, heuristic teaching, consolidating the theoretical foundation, connection is actual, to broaden the students' thinking, expand the scope of knowledge. (4) the quality and ability of education simultaneously. By introducing the requirements of enterprise quality jobs in teaching and occupation ability, to develop the students' occupation quality purposes, not only set a good style of study and examination, and because the theory with practice, can effectively shorten the students to work in time, so that students can better integrate into the jobs in. (5) pay attention to focus on process assessment ability, of the students learning process management, learning ability and learning initiative to improve; pay attention to the students' ability to utilize the knowledge to analyze problems, to solve the problem of.

From 2 to 4 years of construction, in accordance with the principle of "curriculum construction of recombinant basic, reflect modern, trend, comprehensive cross frontier", and strive to Foshan University intelligent measuring course 
construction into a similar course of domestic universities in all aspects of leading quality curriculum, construction of a reasonable knowledge structure and age structure, combination of teaching and scientific research, high-quality teachers. In the continuous improvement of teaching quality at the same time, but also can improve their scientific research level. Trends in higher education and similar studies at home and abroad curriculum, the new educational ideas, teaching methods and teaching methods appropriately applied to the teaching of this course. According to reflect subsequent courses teachers, professors and lectures, teaching statistics results and the students, the teaching effect is mainly manifested in the following aspects:

(1) "intelligent measuring" curriculum, reform and construction of a high starting point, large strength, system is strong, involve wide. New curriculum system, teaching content is rich, the "digital electronic technology", "automatic control principle", "principle", "high frequency circuit", "programmable controller" course content integration and improvement, innovative and exemplary.

(2) "teaching seriously inputs, enrich the content, clarity of train of thought", "the use of multimedia teaching, vivid, succinct language, inspiring and strong, active classroom atmosphere", "energy theory with practice to inspire students thinking, to mobilize the enthusiasm of the students, pay attention to the cultivation of innovative ability". The whole course teaching, demonstration and other methods using real, vivid, impressive, and greatly stimulated the enthusiasm of students in active learning, deepen the understanding of the text.

(3) through the completion of the course of comprehensive practice internship performance, to guide students to pay attention to the training of ability has played a good guide effect, students are very welcome. Students generally feel are as follows: (1) strengthen harvest theory with practical ideas and innovation consciousness; improving the comprehensive ability to use knowledge to solve practical problems; the ability of self-learning ability, access to information and independent problem solving; the cultivation of team spirit and ability to cooperate with others.

(4) a comprehensive, independent design experimental project, so that the students' practical ability, the ability of independent experiment to get a comprehensive training and improve.

(5) give full play to the role of the construction of practical training base, the operation mode of practice teaching base of comprehensive combination of open, perfect the practice teaching management system, innovation of the practice teaching management mechanism, expanding the campus training base for practice teaching function and social service function.

\section{THE METHOD AND STEPS OF COURSE CONSTRACTION}

\section{A. Curriculum construction step}

(1) to review the course syllabus, teaching program, curriculum design and teaching guidance document. Combined with the specific situation of our school teaching management system to build the electrical engineering curriculum has "excellent course" management level; to improve the quality of teaching, set up by the school, hospital, Department of construction of evaluation system of three level curriculum, lay the good foundation for the establishment and improvement of the teaching quality monitoring system.

(2) to deepen the reform of teaching content, to actively participate in teaching reform, absorb the advanced experience of teaching, integrate outstanding teaching achievement, and will be applied to teaching reform. In addition to the reform of teaching content, attaches great importance to practice teaching experiment, practice, through the practice of training and improving the students' innovation ability. The form and content hosting and design practice teaching, strengthen the reform of experimental teaching, offering innovative experiments and research, comprehensive course, encourage students to participate in scientific research and entrepreneurial activity. To speed up the opening of laboratory process, to meet the basic teaching at the same time, phased, step by step to experiment teaching makes full use of resources, and promote students' understanding of the course.

(3) using the advanced teaching means and method, summarize and improve the module course existing settings, make it more scientific, more advanced. Encourage teachers to make network courseware, video production courses, and teachers and students to open on the Internet, the formation of excellent course website, in order to realize the sharing of high quality teaching resources.

(4) to further improve the teaching quality monitoring system, to improve the quality of teaching, set up by the school, hospital, Department of construction of evaluation system of three level curriculum, to lay a good foundation for the establishment and improvement of the teaching quality monitoring system.

(5) formulated the rules and regulations, improve the practice teaching plan, teaching syllabus and a series of teaching files, make the training base system and procedure construction in line with the ISO9000 quality control system requirements.

Define abbreviations and acronyms the first time they are used in the text, even after they have been defined in the abstract. Abbreviations such as SI, MKS, CGS, sc, dc, and rms do not have to be defined. Do not use abbreviations in the title or heads unless they are unavoidable. 


\section{B. To build good network environment}

(1) virtual simulation edutainment: adding a certain amount of flash animation in the multimedia courseware, improving the students' interest in learning and understanding the process of abstraction for work.

(2) cyber source base becomes the students' good teachers and helpful friends: Cyber source base in addition to the curriculum, teaching video, PPT animation, and former follow-up curriculum resources and related Links, provides a powerful support for student learning.

(3) the network interactive platform bridge interaction: college course website is provided with a "mailbox Q \&amp; a", "chat room", let the teachers and students in the direct communication network, realize the interaction between teachers and students, change the single teaching mode.

(4) the real process of real equipment effectiveness significantly: teaching and learning environment of the laboratory, provides production tasks carrier combined, make the students real guns and bullets to exercise ability in the real environment and the working process of the occupation.

(5) the multimedia teaching students specific: the course group of all teachers using multimedia teaching means, multimedia courseware with a lot of pictures, to meet the prerequisite knowledge points under expand the students knowledge, but also increase the amount of knowledge teaching, strengthen the teaching effect in classroom. Gradually increase the online content and the function of the network, such as: add new teaching courseware, experiment, virtual experiment, video lectures, online exercises, online test, online Q \&amp; A, realization of curriculum resources on the internet. Give full play to cyber source advantage, to build a set of textbooks, teaching materials, multimedia courseware, online resources and the network environment in the organic combination of stereoscopic teaching materials.

\section{CONCLUSION}

According to the characteristics and development trend of intelligent measurement based on the analysis of intelligent automation testing course of conventional instruments and technology content, add artificial intelligent detection technology in the course of intelligent measuring contents in the teaching of the concept of BP artificial neural network for teaching practice of automatic detection and intelligent instrument. Into the experiment teaching in the classroom teaching content of the BP artificial neural network is used to design the piezoelectric vibration accelerometer zero output voltage compensation and nonlinear characteristics of the environment of multi parameter sensor intelligent detection system and discussed the conventional automatic control method and integration of artificial intelligence control method advantage. The students master the basic knowledge of BP artificial neural network and the basic methods by experiment. Through the teaching practice of the two students' knowledge teaching into artificial intelligence in intelligent detection technology and instrument course teaching and experiment teaching and good results have been achieved. In recent years, we do a lot of exploration in the teaching reform of intelligent measurement, made some achievements and. In 2014 was named the quality curriculum, curriculum leader and teacher has eight times won the school "classroom teaching quality award" and "award for outstanding teaching quality assessment"

\section{ACKNOWLEDGMENT}

The author wishes to thank the IEEE for providing this template and special thanks to every member provided technical support of this research team.

\section{REFERENCES}

[1] Li Denghua, Gao jingmin., Teaching reform of Detection technology and instrument course for automation [J]. computer education, 2010 (15).

[2] Zhao Rui. "Electrical measurement technology" course teaching mode innovation to explore [J].. Journal of HeFei University of Technology: Social Science Edition, 2010 (2).

[3] Xia Zhelei, Xu Hua, et al. The teaching reform and practice of "electronic technology" course [J]. China electric power education, 2012 (5).

[4] [Xu Yanlei, Li Shijun, Zhou Jing et al. "Electronic measurement technology" course teaching reform exploration and practice of $[\mathrm{J}]$. Journal of Jlin Agriculture Science And Technology College, 2012 (3).

[5] Xia Dongjun, Wang Shicheng, Tao Zeming. Research on the practice teaching reform of surveying course and implementation of $[\mathrm{J}]$. laboratory science, 2012 (3).

[6] Li Aimin, Yan chaode, Wu Liancheng. Engineering survey practice course teaching reform $[\mathrm{J}]$. laboratory research and exploration , 2013 (6).

[7] [7] Lu Feifei The key to improving university teaching quality [J]. higher education of science, 2011 (4). 